\title{
Human Relations
}

http://hum.sagepub.com/

'It's good to be angry': Enacting anger in construction project management to achieve perceived leader effectiveness

Dirk Lindebaum and Sandra Fielden

Human Relations 2011 64: 437 originally published online 10 November 2010 DOI: $10.1177 / 0018726710381149$

The online version of this article can be found at: http://hum.sagepub.com/content/64/3/437

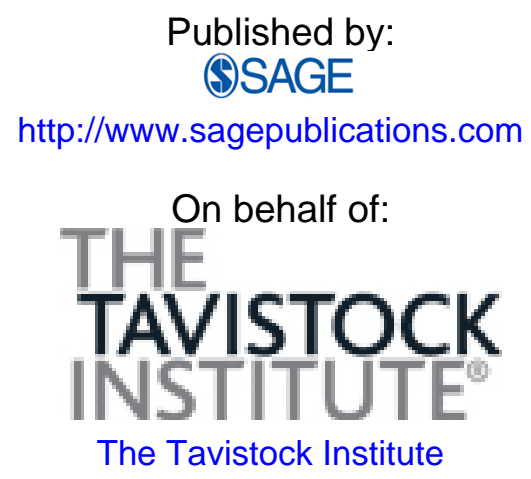

Additional services and information for Human Relations can be found at:

Email Alerts: http://hum.sagepub.com/cgi/alerts

Subscriptions: http://hum.sagepub.com/subscriptions

Reprints: http://www.sagepub.com/journalsReprints.nav

Permissions: http://www.sagepub.com/journalsPermissions.nav

Citations: http://hum.sagepub.com/content/64/3/437.refs.html 
'It's good to be angry': Enacting anger in construction project management to achieve perceived leader effectiveness (c) The Author(s) 2010 Reprints and permission: sagepub. co.uk/journalsPermissions.nav DOI: |0.1|77/00|87267|038||49 hum.sagepub.com

@SAGE

\author{
Dirk Lindebaum \\ University of Liverpool, UK
}

\title{
Sandra Fielden
}

University of Manchester, UK

\begin{abstract}
There is considerable evidence to suggest how positive and negative leader emotions influence a variety of positive and negative follower outcomes. However, little empirical evidence exists to suggest under what circumstances the enactment of negative emotions can yield desirable outcomes for individuals operating in a given organizational context. Drawing upon a series of semi-structured interviews with construction project managers $(n=19)$ from the UK, this study offers valuable insights into how anger is frequently enacted to help individuals ensure the progress of the project, be it in negotiations with other parties or affairs on site with operatives.
\end{abstract}

\section{Keywords}

anger, construction industry, context, leadership, performance

A detailed review of the leadership literature suggests a hegemony of studies examining positive leader emotions in relation to positive outcomes (see Avolio and Gardner, 2005; Bono and Ilies, 2006), as well as studies exploring negative leader emotions in relation to negative outcomes (e.g. Game, 2008; Lewis, 2000; Miner et al., 2005; see also Baruch and Jenkins, 2007, for a commentary). In congruence with the more positive note, George

\footnotetext{
Corresponding author:

Dirk Lindebaum, Lecturer in Management, University of Liverpool, Management School, Chatham Building, Chatham Street, Liverpool L69 7ZH, UK.

Email: d.lindebaum@liverpool.ac.uk
} 
(1996: 84) contends that 'leaders who feel excited, enthusiastic, and energetic themselves are likely to similarly energize their followers', whilst she also draws attention to the reverse, for 'leaders who feel distressed and hostile [are] likely to negatively activate their followers'. However, we question this bipolar emphasis and argue that negative emotions are an inescapable element of organizational life and that, depending upon situation and context, they may not necessarily yield negative outcomes. In fact, from a functionalist perspective, the notion of a truly negative emotion is more myth than reality. As Frijda (2007) claims, all emotions are potentially adaptive states of action readiness, and Fitness (2008: 61) adds that they 'may or may not have destructive consequences'. It is for this reason that Barsade and Gibson (2007) quite legitimately ponder under what circumstances negative emotions can lead to positive organizational outcomes. A lack of answers to that question highlights an important obstacle in developing contextual theories, that is, 'theories that guide us in identifying specific kinds of work conditions and/or events (physical, social, or economic) associated with specific affective states' (Brief and Weiss, 2002: 299).

We posit that the consequences of negative emotions are heavily contingent upon the underlying context, especially in the domain of leadership studies. Our thinking is informed by a resurrected stream in leadership studies that highlights the variability of context, and how this salient factor influences the interplay and interpretation of variables under study (see Fairhurst, 2009; Game, 2008; House and Aditya, 1997; Liden and Antonakis, 2009; Zaccaro and Klimoski, 2001). Thus, the purpose of this article is to examine the contextual circumstances wherein negative emotions can yield positive organizational outcomes. To do this, we apply Barsade and Gibson's question to one of the most men-dominated and aggressive industries: the construction industry (Loosemore et al., 2003; Smithers and Walker, 2000). In particular, we centre upon the function of construction project managers (CPMs) in the construction process and the impact of enacting anger on perceived effectiveness.

For our purpose, we adopt the following views. First, that anger is an adaptive emotion, designed to ensure self-protection in periods of perceived threat or attack (Stanley and Burrows, 2001). These threats may not necessarily be outright lethal, but can be very much symbolic in nature, such as the threatened loss of self-esteem, projected self-image, or status (Stanley and Burrows, 2001). In the discussion, we revisit this argument in conjunction with our analysis. Second, given our qualitative focus detailed later, we stress that our findings should be interpreted accordingly. That is, we conceive of perceived leader effectiveness as an accumulation of lived experiences that contribute to the leader's understanding that certain behaviours (i.e. anger) can yield favourable outcomes for him or her given the context and situation (see Roberts Callister et al., 2003). Of course, this is influenced by, and contingent upon, the reactions CPMs obtain from their colleagues. If anger would be an illegitimate or inappropriate behaviour in construction, it would be questionable whether CPMs would enact it to be effective in their job. It is, therefore, expedient to bear the issue of anger legitimacy in mind throughout our article.

The article unfolds as follows. First, we illustrate the role of emotions in the context of construction. Second, we draw attention to the positive outcomes at work that are related to the enactment of anger. Third, we frame the study within the wider domain of management 
studies and clarify several core assumptions we adopted in this analysis. We then report findings from qualitative study.

\section{Emotions in the context of construction}

The management style of many in contracting companies is based upon the street fighting man. Banter and joking, usually at the expense of others, is used for point scoring when things are on a reasonably even keel. If that fails or the pressure is great, verbal abuse and shouting are the weapons to instil fear and maintain power in the office corridor. (Smyth, 2000: 12-13, emphasis added)

The introductory vignette rather dauntingly delineates the parameters within which the typical management style in construction tends to fall. This is not an isolated case, and similar, if not more explicit, examples abound in the literature (e.g. Loosemore and Chau, 2002; Loosemore and Galea, 2008). In light of the above quote, we adopt Zeelenberg and colleagues' summary concerning the key aspects of emotions. According to them:

... emotions are acute, they are relatively momentary experiences. This differentiates emotions from moods, that typically last longer, and from other more general affects. Emotions are about something or someone: you are angry with someone; you regret a choice ... Emotions typically arise when one evaluates an event or outcome as relevant for one's concerns or preferences. (2008: 20)

When Solomon (1993) suggests that emotions signal an individual's engagement with the world, one may reasonably assume, based upon the introductory quote, how that engagement manifests itself in the context of construction. Thus, it appears safe to portray construction as an emotionally charged environment. After all, wherever there are fierce competition and adversarial relationships, it is the emotions that renders them as such.

To a significant degree, this adversarial atmosphere is influenced by the mendominated culture in construction (Fielden et al., 2000), which has important implications for the nature of power structures in construction organizations (Cartwright and Gale, 1995). According to Parkin (1993), men preserve dominance of the public domain, reflecting 'the world of goal-directed organisations, the world of politics, the world of dispassionate reason, and the world of the "productive"" (1993: 181). Domagalski (1999) extends this view by suggesting that emotionality is chiefly defined within a male power structure that values 'emotional strength', connoting repression of, and control over, emotions. However, we argue that this repression pertains almost exclusively to soft emotion, such as empathy, and does not exclude anger as such. Note that anger is described as a powerful emotion (Keltner et al., 2003).

In congruence with the above notion of emotional strength, the performance of men in construction tends to be assessed against 'a particular stereotype which supports and promotes decisiveness, toughness, self-reliance, resolution and control' (Loosemore and Galea, 2008: 126). Hence, context greatly limits what behaviours are considered prototypical 
(e.g. Lord et al., 2001). As Mischel (1977) noted, the more intense the situation, the more salient the norms are that inform behaviour. Therefore, behaviours of the types depicted above may be a prerequisite for surviving as a CPM in construction, especially against the backdrop that construction is consistently characterized by aggressive/authoritative management styles (Giritli and Oraz, 2003; Smithers and Walker, 2000), adversarial relationships (Holt et al., 2000), tight profit margins (Agapiou et al., 1998), fierce competition and the imperative to be able to respond to extreme short-term pressures at work (Dainty et al., 2002). It is, therefore, not surprising that this results in the industry's preference to recruit assertive candidates (Raiden et al., 2004), who are perhaps better able to cope with the 'survival of the fittest' maxim (Cartwright and Gale, 1995). The case of a CPM detailed later strongly underscores this point. Thus, there is evidence to suggest that there is a normative legitimacy underlying the enactment of more decisive and assertive behaviours in construction (see Loosemore and Galea, 2008).

However, it would be mistaken to presume that only context dictates what behaviours are considered prototypical. While contextual factors may be eminent, we must recognize that individual attributes are fundamental to the shaping of organizational behaviour (Schneider, 1987), thereby creating a cycle of mutual reinforcement. Of note, there is evidence to suggest that science and engineering students tend to be more authoritative than social science students in the first place (Kafetsios et al., 2009), which then impacts upon the shaping of organizational behaviour. Under these conditions, it is germane to explore and better understand why CPM use anger in order to succeed.

\section{Positive outcomes related to enacting anger}

Interestingly, studies in social psychology have long recognized that anger is related to enhanced status conferral (Tiedens, 2001) and better outcomes in negotiations (van Kleef et al., 2004), while business and management scholars only recently turned their serious attention to it (see Gibson and Roberts Callister, 2010, for a review). This development is accompanied by recent commentaries and interviews with leading psychologists, suggesting that the widely held view of anger as detrimental behaviour at work is mistaken (Baggini, 2009; Hill, 2009). For instance, Tiedens (2001) ascertained in a series of experiments that those expressing anger enjoy higher status conferral and are seen as more competent by others. In addition, Antonakis (2003) seriously doubts whether an emotional outburst is detrimental to leader effectiveness. On the contrary, he posits that emotional outbursts can be conducive if timing and dosage are appropriate. Further examples from negotiation studies demonstrate positive effects of anger. Van Kleef et al. (2004) found that a negotiator who faces an angry counterpart is more likely to back off than a negotiator who faces a happy counterpart. Akin to the high-pressure environment in construction and the direction of anger downward in power relationships detailed in the analysis, van Kleef et al.'s experimental study occurred under high time pressure and when the negotiator who faced the angry counterpart had lower power.

It follows thus that anger is intimately intertwined with issues of power (Keltner et al., 2003). Formal power relationships often penetrate organizations (Pfeffer, 1981) and organization charts habitually place line managers above and team members below in terms of focal managers (Harris and McCaffer, 2001). With this comes typically an 
understanding of what behaviours are deemed appropriate or inappropriate upward and downward in the power hierarchy. In addition, "power is context or relationship specific in that a person is not "powerful" or "powerless" in general, but only with respect to other social actors in a specific social relationship' (Pfeffer, 1981: 3), Thus, the contextual limitations of enacting anger are also underscored by observations linking the use of anger to settings where it is 'considered normatively appropriate' (Gibson and Roberts Callister, 2010: 74). Inherent in the above outline is thus the legitimacy of anger, and that is closely related to organizational cultural norms. As discussed in Gibson and Roberts Callister (2010), the closer the expression of anger is in line with the organization norms for appropriateness, the more likely positive consequences may manifest themselves. Seen in this light, it is not surprising that anger is sometimes associated with stronger leadership (Bass and Stogdill, 1990) in situations where its use is deemed legitimate. It should be noted, however, that the poor quality of interpersonal relationships in construction is a long-recognized contentious issue (Egan, 1998; ODPM, 2004). As several scholars note, construction can only improve its performance by developing a better grasp of the interpersonal dynamics of its employees (Dulaimi and Langford, 1999; Loosemore et al., 2003). Still, empirical evidence continues to indicate that construction is surely no 'touchy-feely' industry, and that intimate and comfortable relationships are usually not formed between CPMs and subordinates (Butler and Chinowsky, 2006).

\section{Framing the study}

It is critically important to point out two guiding issues that informed this study. First, the lens we apply in this study is behavioural in nature. In other words, we are not concerned with the influence of emotions on certain cognitive decision-making tasks, but rather with the behavioural prescriptions attached to a specific type of occupation. We are aware of the significant corpus of research that studied the role positive and negative emotions in decision-making tasks (see George, 2000, for a review), and that both serve vital roles in organizations (Ashkanasy et al., 2002). Therefore, in this article, we are concerned with how negative emotions can yield positive outcomes for an organization, even though impaired cognitive information processing may occur at the individual level. Further to this, our focus upon how negative emotions can yield positive outcomes may introduce a conflict; whereas the use of negative emotion (in this case anger) as a central characteristic of one's role may help one be effective in the job, one pays also a price in terms of physiological costs (Steptoe et al., 2000). Hence, being effective in one's job by using anger may mean high stress levels and physiological arousal both for one's self and colleagues. The crucial distinction here is organizational short-term gain and not the long-term well-being of individuals, though the latter is not a focus of our analysis. Second, we centre upon the enactment and not the expression of anger. Stated differently, acting angrily is not the same as communicating in a serene manner that one feels angry. In so doing, we acknowledge Loosemore and Galea's (2008) earlier point that performance of men in construction tends to be assessed against toughness and decisiveness criteria, among other things. It is the acting out of anger, not necessarily its mere expression, that would be seen as fit for the context. 
In our study, we were interested in the lived experiences of CPMs in terms of how they enact anger to attain favourable results. As these are filtered through the context of construction, Grint (2000) quite rightly notes that "what counts as a "situation" and what counts as the "appropriate" way of leading in that situation are interpretive and contestable issues, not issues that can be decided by objective criteria' (p. 3). Brief and Weiss (2002) concur, arguing that perceptions of employees in their work environment are not, of necessity, synonymous with more objective evaluations of work-related incidents. In line with several other scholars (Fineman, 2004), we deem a qualitative approach to data collection most suitable for our purpose (see also Bresnen, 1995). Therefore, a qualitative study that examines how CPMs enact anger in the pursuit of goals has the capacity to contribute significant evidence to our understanding of perceived leader effectiveness.

\section{Method}

We draw upon the qualitative data component of an ongoing mixed-method investigation (see also Lindebaum and Cartwright, in press) into emotional intelligence (EI), transformational leadership, and their implications for performance in construction project management, so as to detail the use of emotion (as one component of the EI construct, Mayer and Salovey, 1997) in relation to perceived leader effectiveness. The current study was embedded within a realist research paradigm, which sees reality as 'only imperfectly and probabilistically apprehensible' (Helay and Perry, 2000: 119). Under this formulation, interpretation of findings by qualitative and quantitative methods can indeed occur, though critical voices do also exist (Bryman, 2007).

In so doing, we take a distinctive position akin to those writers who are interested in phenomenology as a way of eliciting perceived experiences of individuals under investigation (e.g. Dasborough et al., 2003; Fineman, 2004; Sandberg, 2005). Seeing from this perspective, the 'person and world are inextricably related through lived experiences of the world' (Sandberg, 2005: 43). In our study, this implies lived experiences of CPMs in relation to perceived leader effectiveness. Whilst this perspective is not without its limitation (Antonakis et al., 2004), there is a pressing need to conduct a study that privileges the views and the meaning that participants append to the phenomenon in question (Dey, 1993), not least owing to their important impact on the behaviour individuals enact (Bryman, 2004).

We sought to increase the validity of our study by means of Sandberg's (2005) criteria for establishing validity in qualitative research. Specifically, we borrowed his notion of communicative and pragmatic validity to underpin the conclusions drawn from the interview data. In brief, communicative validity is a 'criterion for establishing truth as perceived fulfilment' (Sandberg, 2005: 54) and can be attained, inter alia, by discussing the findings with professionals in the practice being examined. To this end, the mixedmethod study was supplemented with respondent validation (Bryman, 2004), whereby the major findings of the study were fed back to participating CPMs ( $n=5$, for respondent validation) in the form of a brief research report that contained both quantitative and qualitative findings. These reflections are woven into this article, where appropriate. Pragmatic validity, in turn, can be seen as a 'criterion for establishing truth as fulfilment in practice' (Sandberg, 2005: 54). That is, the researcher obtains 'true' knowledge of what emotions actually are through the lived experience of using emotions in a particular 
context. In this respect, it is important to stress that this study was heavily informed by the first researcher's background in construction (i.e. undergraduate and postgraduate degrees in construction engineering and management as well as several internships on site).

\section{Sample}

Our sample constitutes a non-random purposive sample (Naoum, 1998). In total, 19 semi-structured interviews were conducted with CPMs employed at four different UK construction organizations. The role of CPMs is of intrinsic interest here, for they oversee 'the day to day control of the process conducted on site including liaison with the architect/civil engineer regarding instructions, payments, progress meetings, and commercial dealings with sub-contractors, etc' (Harris and McCaffer, 2001: 313). This implies an immense centrality of the CPMs' function, especially with a view to ensuring the success of the project (Calvert et al., 1995). To this effect, CPMs have to relate to a variety of different parties involved in the construction process, such as clients, architects, and operatives on site (Harris and McCaffer, 2001). Note that scholars increasingly point to CPM's function in the leadership process of the project (e.g. Toor and Ofori, 2008), since project management implies both people leadership and task management (Huemann et al., 2004). Further to this, Bresnen (1995) argues in his leadership study (embedded in construction) that managers are often presumed to behave like leaders, regardless of whether they display de facto leadership qualities. From there, it is appropriate to situate our study in the wider domain of leadership studies.

The sample size was influenced by the circumstance that, after the 16 th interview, CPMs did not produce any significant new data, concepts, or themes, hence indicating what Lincoln and Guba (1985) describe as theory saturation. This size is, furthermore, in line with previous qualitative studies, which found that variation of a phenomenon in question reached saturation at round 20 participants (Alexandersson, 1994, cited in Sandberg, 2000). All CPMs interviewed were white British men, aged between 26 and 62 years, and were in charge of the day-to-day running of a construction site, as defined prior. Years of experience ranged between one and 35 years and, in general, older CPMs (i.e. above 45 years of age) attained their positions after having started as craftsmen on site (e.g. joiner), whilst many younger CPMs (i.e. below 35 years of age) had completed a university degree prior to embarking upon a career in construction. Note that the CPM ID numbers are followed by their age (in parenthesis), so as to highlight any differences in reaction between the younger and older CPMs that potentially exist.

\section{Procedure}

Senior directors of the respective organizations provided the contact details of the CPMs and these were contacted via email on a random base. Prior to the interviews, a statement detailing the rationale and background information to this study was provided to all potential participants. Duration of interviews amounted to 30-60 minutes on average and they were conducted at the participant's construction site. All CPMs agreed to their interviews being tape-recorded, with one exception where notes were taken during the interview. To ensure accuracy of notes taken, the first researcher read out loud the statements 
noted down during the interview to the respective CPM subsequent to the interview. All other interviews were transcribed in full.

The underlying maxim throughout the interviews was to invite CPMs to reflect upon and narrate situations that they experienced within the functions as CPMs. To achieve this, questions were raised and the CPMs were invited to elaborate upon them in any detail they deemed fit. For instance, questions sought to explore whether emotions are important to the job of CPMs and whether they believe that emotions (positive or negative) can assist in solving problems. CPMs were invited to frame their responses around situations they experienced at work. Initial responses to these situations were often followed by questions like 'why would you act like that?' or 'can you explain that further?' to elicit more details. To safeguard anonymity, interviewees were instructed not to reveal any personal or company information that would enable their identification in retrospect.

\section{Data analysis}

Template analysis (King, 2004) was employed to analyse thematically the accounts produced in the semi-structured interviews. By now, template analysis is widely used as a technique to analyse textual data in organizational behaviour and management studies (e.g. Cassell, 2005; Palmer et al., 2004; Poppelton et al., 2008; Randall et al., 2007). The rationale for selecting it emanates from the fact that other techniques, such as grounded theory, can be too prescriptive in that it specifies the procedure that must be followed (Strauss and Corbin, 1998). Template analysis, in comparison, proffers more flexibility with fewer specified procedures, and enables researchers to tailor it to the requirements of the respective study (see King, 2004, for a contrasting analysis of template analysis and grounded theory). In template analysis, it is normal to stipulate themes that reflect specific areas of interest a priori and often these themes reflect the content of the interview guide. But, as King (2004) cautions, these should be modified as the researcher's understanding of the data and their interconnectedness deepens. In our study, the interview guide of our study reflected, inter alia, the sampling domains of the EI questionnaire used (i.e. the Wong and Law Emotional Intelligence Scale, Law et al., 2004). For the purpose of our study, we centred upon the use of emotions (as one dimension of the above EI measure). However, a careful reading of the interview data suggested that this primary theme would be too narrow to reflect the breadth and depths of the data provided. Driven by emerging strands in the data provided by CPMs, we considered it necessary to further decompose this theme into three subsidiary ones, namely i) different approaches to using emotions in the workplace, ii) anger in context, and iii) legitimizing the enactment of anger. In line with the principles of template analysis (see King, 2004), these themes should be seen as mutually informing and related. In what follows we describe and examine the major issues raised by participants in terms of the different approaches taken.

\section{Different approaches to using emotions in the workplace}

This study highlighted that, while there was a general acknowledgement of the centrality of emotions in construction project management, there was evidence to suggest that CPMs took different individual approaches to how they use emotions in the workplace: 
To make our business work you've got to become a good people person. If you get a grip of those emotions and you get a grip of what makes people tick, yeah? That is the key to a project being a successful one that makes money and everybody's happy or one that loses money and upsets the client. (CPM 17 (40))

His comment is in line with the suggestions made by CPM 2 (32), who further underpinned the central role of emotion in the management in construction projects. To him, emphasis upon emotions is a critically influential factor that decides the project's success or failure, respectively. More precisely, he argued that:

I think they're, well, they're one of the key management tools we have, i.e. if you understand emotion you can help manage people as individuals far better than being emotionally detached ... I would say they're key.

What is instantly striking is the reference to emotion as a key management tool, albeit he does not specify what type of emotion he has in mind in the above statement. CPM 15 (34) suggested that the time for ill-tempered individuals in construction may be over by referring to the absence of shouting:

There's no room in this industry any more for hot-heads and all that screaming and bawling ... People who are just sort of like divorced from the whole environment around them.

However, an almost complete absence of critical self-reflection became conspicuous in the interview with CPM 6 (57). Indeed, prima facie he appeared very aware of who he is and how he comes across to others:

I'm forceful but if I've been given a job to do, I've done it. That's how I am, that's my nature. You won't change me. And the director said that to me, a couple of days ago, he said, 'I know you're hard, I don't want to change you, but just relax a bit. Can you come down a little bit?' ... I'm very forceful with people, people listen. When I go out, if one of my managers can't get something done out there, if I go out it gets done. You know, that's how I am.

Despite his awareness, he was told to come down by his director. And yet, he concurrently admits that no one is likely to change him. What cannot be said with certainty is whether he knows how others feel and think about him and cannot be bothered to change, or whether his professed awareness is simply an illusion. This statement also ties in with another rendition he provided with regard to him securing repeat business from a major client, as detailed later.

\section{Anger in context}

Overall, there was a distinct preponderance of accounts indicating that, when pressure is intense, CPMs tend to be rather short-fused, taking recourse to anger to ensure progress of the project. The account of CPM 8 (55) points to a potential explanation for this. Note that this is a direct contradiction to what CPM 15 (34) stated above (i.e. no room for hot-heads): 
I think the kind of people the industry attracts, you know, are the less well-disciplined ... much less well-disciplined ... even within the professions . . . I think people do reflect their environment as well.

One may detect, at least in part, an underlying rationale for the above statement in the account revealed by CPM 5 (44). He suggested that, because of its size, the organization he works for is 'driven by systems and procedures rather than personalities'. He went on to suggest that individuals are not assessed on 'emotional things', but instead on 'fact and figures'. CPM 4 (39) believed that someone who brings emotion openly into the workplace will not get very far in construction. Overall, he believed that construction is 'not very receptive ... (laughs) as an industry to emotional things really'. In aggregate, however, this non-receptiveness to emotion appears to exclude the feelings of anger and frustration.

In conjunction with their admission that anger is relatively frequently used as means of drawing an issue to a conclusion, there was also the recognition by many CPMs to control their emotions at work. CPMs testified that they definitely had to restrain themselves, for example, during project meetings, be it owing to an inappropriate or untrue comment or personality clashes. The context and nature of power relations in these meetings were seen as an important factor. That is to say, in a meeting with a design team and clients the imperative to control emotion is higher than for a meeting with contractors, the latter of which tend to have a lower position in the project's hierarchy. Arguing from many years of experience in construction, CPM 3 (37) described the seething feelings and the control thereof as follows:

You just wanna rip these people in half sometimes, but you've got to bite your lip as well at the same time. So you've got to have a bit of passion about it.

However, one, and only one CPM, specifically addressed the argument of conduct in construction. He elaborated the following:

In this industry you've got to be very, very careful, not just what you say as a CPM, but how you conduct yourself and how you go about your business and how you talk to people. (CPM 3 (37))

This sentiment was expressed by others, but in rather different ways. In a situation where CPM 3 (37) was infuriated by an inappropriate comment by a colleague during a project meeting, the context served to influence how anger was enacted:

Let the meeting finish, get them into the room, bollock 'em ... If they've said something that's out of order, ... that frustrated me or annoyed me so much, I would have to let them know where I lie on the subject of what they've done in that meeting. If they've embarrassed me or they've embarrassed the company . . . and I've been there, and this has happened in the past, and the best way to deal with it is get that person in the office, shut the door and you can fucking well tell them, (laughs) all right. 
As a result, in such situations, several CPMs admitted to have difficulties to regulating their anger. This would manifest itself as being very affirmative, though in most cases not below the level of decency (i.e. not swearing and insulting). In stark contrast, CPM 6 (57) was outspoken about a recent Health and Safety issue he witnessed and resolved on his site:

I lost it on the subcontractors, and the site manager told them every time they went out they wasn't wearing safety helmets, they wasn't wearing eye protection and they wasn't wearing their gloves. So I went up there with him. I said, 'Look, lad, put your helmets on'. And this one, 'Effing this, and effing that'. I wasn't being awkward with him, I just wanted him to put his helmet on. So I lost it with him, didn't I, effing and blinding at me. So I lost it proper. 'Get off that scaffold, get off this job now. If you don't get off that scaffold and go I'll have the police here to remove you'. So what happened was I lost it with him, and it'd took us ages to get these people on site, this specialist company, and when he walked all of them walked, they were all in one car. So I lost the lot of them (laughs) and we had to start all over again. So, I did lose it then, I do at time to time. If someone's being awkward with me or having a go, I am like that.

What becomes apparent from the above is that the operative's failure to comply with the CPM's request to wear safety equipment triggered an intense response in him. Ultimately, this led to the departure of the entire specialist company, thus impacting on the project's progress (i.e. 'we had to start all over again' (CPM 6)). Whilst this situation, as a standalone incident, would indeed suggest that his lack of emotional control had detrimental consequences in the short-term for the project, his later reference to being awarded repeat business worth several million pounds suggests that this obstacle did not prevent him in the past from satisfying the clients. However, some CPMs also understood that expressing anger is a directional issue. That is, they may express it to individuals or contractual parties with lower power, like operatives on site or subcontractors, but not their line managers. This selective point is clearly conveyed in the words of CPM 19 (44). To quote:

You've got to relate to people at their level ... You've gotta tailor your response to the audience that you're with.

Hence, several CPMs seemed to have a differential understanding of power relations, which implied an understanding as to when and to whom they can express anger. Knee-jerk reactions of the kind describes above are incidents some CPMs were eager to avoid, asserting that they are not keen to be associated with them. Circumspection appeared to be of paramount importance for them, for an erratic and non-deliberate response was seen as unprofessional and not conducive. CPM 17 (40) expressed this as follows: 'I wouldn't want to give the impression to anybody else in that design team or project team that I knee-jerk'. Yet, the above accounts also suggest that such tendency may weaken under the immense pressure permeating construction. 


\section{Legitimizing the enactment of anger}

The use of emotions in the workplace is generally legitimized, either in terms of the organizational culture (normative), or they are justified through irrefutable reasoning (causal). However, as can be seen from this study's findings, these two approaches are often intertwined. For example, CPM 2 (32) reported that he 'is forced by the culture to be tough', for otherwise he would be 'run over'. As a result, more benevolent or emphatic behaviours (e.g. 'let the guys go earlier') would quickly incur him the reputation of being too soft. Therefore, such behaviours were seen as disadvantageous. CPM 18 (32) subscribes to the same notion, saying that on large projects he has to be stricter (and sometimes harsher) with his staff so that they 'fly along with the project'. Not only has one to be forceful with others occasionally (e.g. CPMs 6, 5, and 18), but also one has to appear stressed to be seen as productive (CPM 2 (32)). The latter CPM felt that it would not be conducive if his colleagues and team members would ask themselves: 'why is he so relaxed all the time?'

Interestingly, other CPMs were also quick to mention that anger, carefully dosed, was conducive to resolving a problem in their favour. They appeared to employ anger in a deliberate fashion after initial requests to carry out a certain task or highlighting their perspective on a particular issue did not yield desirable results for them. For instance, CPM 1 (62) was explicit in his approach to request a certain task to be executed, stating that he is habitually courteous with other people, but that he 'comes down hard on them' if they fail to comply. Object lessons in this respect are proffered by CPM 5 (44) and 2 (32). As with other CPMs, there was a strong sense that they habitually regret using anger to resolve a problem, yet would readily do so because things get done this way. For instance, shouting and bawling was used by CPM 5 (44):

We get certain contractors ... that are very arrogant, very brash, and they have to be perhaps dealt with a bit more firmly ... You have to meet their over-arrogance about their own performance in a different way really. It's no good being too gentle with them really . . There was a particular contractor that was actually doing brickwork for us, that wasn't really meeting their obligations and the best way to get, you know, them to improve, wasn't really to shout and bawl at them and enter into a row over it. But that's the way it became really ... But probably shouting and bawling isn't one of the most skilled ways, but might be appropriate at certain times.

Whilst admitting that his conduct may not be the most skilled way, he eventually used shouting and bawling in order to resolve the problem. CPM 2 (32) produced a remarkably similar account, though here intentionality is more conspicuous than in the previous quote:

Not too long ago in a project meeting I had a rather emotional outbreak with the structural engineer, on the basis that they were trying to turn the tables contractually without any justification, and it had been going on for quite a while ... It was drawn to a conclusion with an emotional outburst, I'm afraid. Retrospectively did I regret it? Probably not, actually, because it resolved the matter . . The outburst was a decision that was made by myself, it wasn't emotionally uncontrolled, it was a controlled outburst. It came after a point when something had developed and wasn't moving on and had been discussed for a while ... I saw the outburst as bringing something to a conclusion beyond that of basic contractual discussion. 
Noteworthy is his remark 'I'm afraid' when reflecting upon the fact that it came to an emotional outburst, which he did not regret after all. Others put it more diplomatically, suggesting that they would 'raise their profiles' to lend more visibility to their presentation (CPM 13 (37)).

However, cautionary words were expressed by some CPMs, which was most evident in the account of CPM 18 (32). After an incident on site made him feel very upset and swear at his operatives, he critically evaluated the potential consequences thereof:

It [being angry] worked, it had the response I was hoping it would, everybody went out onto site and what hadn't been addressed was actioned straight away, so all in all it worked. I think if that happened often, you know, if you were always speaking to people, swearing at people, eventually it would reach a point where it wouldn't have an effect. So if you use it every once in a while, I think it works.

Yet, whilst he felt that he had a legitimate (i.e. causal) reason to be angry, as it got things done, he seemed to understand the limitation of this approach. It is safe to say that the previous example indicates some degree of reflection on his behavioural response to the situation described above. Also, instead of letting the anger roam unfettered without explanation, he believed that emotion attains maximum impact if its display is coupled with an explanation as to why he feels like he did. Hence, it would be simplistic to suggest that anger was a normative emotion and that the 'anger' mechanism would always function and retain its influence. Still, a predominant approach in the use of emotion was the recourse to anger or aggression toward other individuals or parties. This seemed especially fuelled by the need to attain goals in the fast-track nature of construction. After all, as CPM 19 (44) put it, 'we've got all to deliver'. CPM 12 (53) put it even more affirmatively in the feedback session, maintaining that 'if we don't have a profit, we don't have a business. Full stop'.

Many CPMs converged on the notion that anger and frustration are the most frequently experienced emotions at work. The degree to which some CPMs have experienced anger is conveyed in what CPM 14 (68) commented on this issue:

There's times when . . . there's been some incidents when I'll feel very upset, very angry, and that will . . . affect me when certain things happen . . . I think it's probably other people not giving things the same level of importance as I do, so then I feel that they should do, and then therefore I feel . . . really the raw emotion is anger really, towards them.

Notable in the above excerpt was his reference to anger as a raw emotion, especially when others do not live up to his expectations. In this regard, breaches of health and safety regulations and non-compliance with promises rendered were frequently seen as catalysts giving rise to anger and frustration. For many CPMs, integrity and honesty were highly regarded characteristics. The preceding quote is also indicative of how intimately emotion and thought are intertwined. There, anger arose in response to an evaluation where others were considered to not comply with his expectations.

It is worth recalling the view of CPM 6 (57) discussed in the first theme above, where he explicitly admits that he is a forceful character, even though his director told 
him to 'come down a little'. Given his uncompromising attitude toward the self-perceived legitimacy of his forcefulness, one may reasonably suggest that it is a preferred mode of behaving that is internalized to such an extent that a questioning of its appropriateness does not seem necessary. Either way, it is less disputable that others expressed their concern about his forcefulness. This did not seem to affect the success he enjoyed with the projects under his supervision. The excerpt below gives expression to it:

They're [the clients] happy with me on phase one, they give me phase two, they give me phase three, phase three, they give me section four or they give me this out here, [a project with a] value of a hundred and eighty odd million. (CPM 6 (57))

At the discretion of the client, he was repeatedly awarded a number of phases for a major project. This would seem to suggest that primacy is given to meeting the clients expectations (i.e. 'they were happy with him'). True, his forcefulness is addressed as an issue of concern, but he appeared adamant in his attitude that no one can change him and, implicitly, knows that his way of conduct gets results. This view represented an extreme way of conduct, and was indeed not shared by all other CPMs.

\section{Discussion}

This study set out to highlight the conditions and circumstances under which the use of anger can entail positive implications for the individual and, by extension, for the organization as well. In so doing, we addressed a research topic about which little empirical research is available in the extant literature. From the outset, we applied a clear demarcation between the role and effects of emotions in individual decision-making tasks, where individuals are less subject to the constraints of their environment, and those situations in which individual decision-making may effectively be impaired as a result of intense emotions (i.e. anger), but where the resultant behaviour nevertheless yields desirable outcomes for them and their organization.

The accounts produced by CPMs were contextually rich and proffered an insight into the predominant behaviours they enact in order to succeed in the adverse working environment of construction. Foremost among the findings is the striking detail that CPM relatively easily and quickly take recourse to anger irrespective of age, to resolve an argument or gridlock in negotiations in their and hence their organization's favour. However, the achievement of desirable outcomes, through the legitimate enactment of anger, is possibly short-lived in nature, as individuals may pay a price in terms of physiological costs (Steptoe et al., 2000) when anger becomes part and parcel of a CPM's behavioural repertoire. Note, however, that this a somewhat speculative argument that requires further empirical investigation, as pointed out below. It is at this instance that the article contributes valuable theoretical evidence to our understanding of the lived experience of CPMs in relation to perceived leader effectiveness.

\section{Theoretical contribution}

To highlight the contextual nature of perceived leader effectiveness, it is worth explicating anger in greater detail, especially why it can erupt so readily in the present context. 
As alluded to earlier, Stanley and Burrows (2001) consider anger an adaptive emotion, designed to ensure self-protection in periods of perceived threat or attack. They also posit that these threats need not be outright lethal, but can also be symbolic in nature, such as the threatened loss of self-esteem, projected self-image, or status. On the more symbolic side, hence, anger is frequently seen as an interference with achievement. In construction, achievement (and for that matter progress) is of paramount importance. Any delay in the progress of projects can spell disaster for the organization. Several CPMs concurred that the penalty systems in place for missing targets can spell disaster for a company. For instance, if a project is handed over late by a week, liquidated damages for the additional period can be considerable. The purpose of liquidated damages is to agree in advance what should be paid by the contractor to the client in the event that construction works overrun. One CPM provided the example of $£ 70,000$ in liquidated damages per week for a recent project. Of note, several CPMs hinted in the feedback sessions that 'blowing one's trumpet' (CPM 2 (32)) and showing off one's accomplishments is fairly customary in construction. CPM 1 (62) put that rather bluntly, stating that his ' $\mathrm{CV}$ is the best in the company'.

It is at this juncture that a very potent catalyst for the eruption of anger emerges. At times, obstinate and passionate commitment to a particular course of action can turn into a fixation, regardless of consequences (Staw and Ross, 1989), and this can also imply sustaining a consistent image of oneself (Forgas, 1985). That is, in the case of CPMs, being seen as an achiever. Thus, any interference with achievement is seen as symbolic threat to losing one's achiever image. As mentioned earlier, the assessment of performance is often i) based upon facts and figures and ii) occurs against particular stereotypes that constitute very specific social presentation needs for CPMs. To be seen as an effective CPM, they may have to display anger on occasion, perhaps even against their volitions, to raise the visibility of their presentations. This may be further fuelled by the fast-track nature of construction, fierce competition, and the need to meet extreme shortterm pressures of the project (Bryman et al., 1987; Dainty et al., 2002). Anger then, may be displayed as a result of three salient factors. First, the fear of losing one's reputation as an achiever seems distinct (i.e. negative reinforcement) and, therefore, the likelihood increases that an individual's behaviour will recur to this effect (Arnold et al., 1991). Second, it serves as a vehicle to engender results favourable to CPMs and their organizations, as indicated in the present analysis. Underlying this is a process whereby meaning and priorities CPMs attach to the project is conveyed to both subordinates on site as well as other parties implicated in the construction process (e.g. subcontractors). Third, it is an integral tool for securing and sustaining those social presentations or impression management needs so idiosyncratic to construction. As such, anger is often acted out through the prescriptions and demands of CPM roles. Thus, anger appears to be embedded in the occupational culture of construction and embraces a strategic and legitimate function to be successful as a CPM (see also Fineman, 2004; Gibson and Schroeder, 2002). This line of reasoning, along with several characteristics of construction, is depicted in Figure 1. In line with our introduction, it should be noted that the interplay between the characteristics of construction and individual ones is that of mutual reinforcement, as the context dictates certain behaviours that individuals also bring into the workplace by means of their attributes. The arrows in the left box between construction and individual characteristics indicate this. 


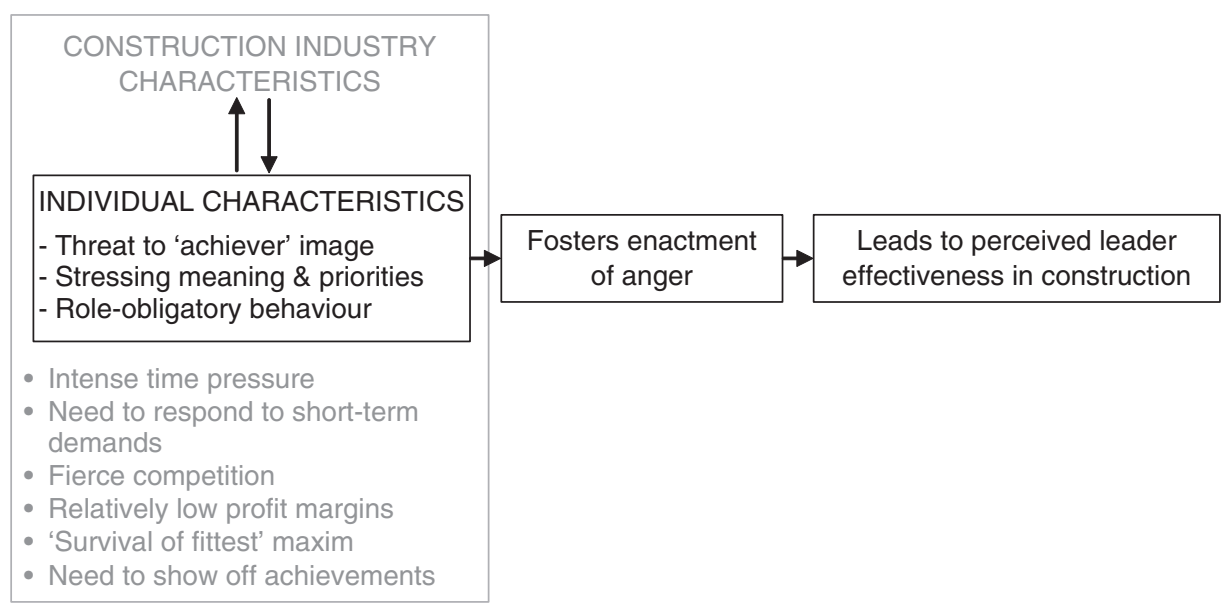

Figure I External and internal factors giving rise to the enactment of anger and its effects upon perceived leaders' effectiveness in construction

It appears then, that Bass and Stogill's (1990) observation that anger is sometimes associated with stronger leadership should be heeded more than has been done in the past. Also, the studies cited earlier from social psychology further underpin the view that anger can favourably influence how others confer status as well as negotiations outcomes. Therefore, the combination of the present analysis with the empirical findings discussed above, strongly suggests the pre-eminent role anger can play in attaining desirable outcomes, particularly in the context of construction.

Given these synthesized findings, the argument that the expression of anger suggests lack of emotional regulation and is persistently associated with leader ineffectiveness, as posited by popular as well more scientifically inclined writers (Goleman, 1998; Prati et al., 2003), becomes a rather untenable position. Even very recently, scholars have argued that anger may 'interfere with the leader's goal to comply with display rules by remaining positive and upbeat when interacting with followers' (Gardner et al., 2009: 469). Thus, rather than seeing anger as role-violating behaviour (Lewis, 2000), it appears that it is a role-obligatory behaviour of CPMs, a vital ingredient in decisive and defining moments of the project, especially when it is directed toward parties with lower power. In effect, it is intimately entwined with the roles CPMs perform within the intricate and fragmented process on project sites. Therefore, Lewis's (2000: 222) suggestion that 'in a specific organisational context, choosing appropriate emotions to express reflects a leader's ability to respond in an effective way' appears correct. Taken together, then, it is plausible to support Liden and Antonakis's call that 'scholars must consider context in leadership research’ (2009: 2), especially if context dictates role-prescribed behaviours.

\section{Limitations and future research}

Despite the valuable insights that our analysis offers, there are some important limitations that must be recognized. More generally, qualitative data do not permit the testing 
of theory (see Creswell, 1994) and are subjective in nature. Even though attempts were made to enhance the validity of our findings (i.e. communicative and pragmatic validity), our own perception as an influencing factor in the interpretation of findings cannot be precluded fully. Moreover, this study is limited because it did not incorporate the views of those subject to the anger displayed by CPMs (e.g. subordinates and team members). Since some scholars argue that leadership is socially constructed phenomenon (e.g. Meindl, 1995), it would be pertinent to explore the views of those that help produce and reproduce the process over time. In this context, it may be promising to examine the nascent research field of toxic emotions (e.g. Lawrence and Jordan, 2008). Specifically, how do followers cope with the exposure to anger given that they are often compelled to suppress their emotions as a result of being lower in the power hierarchy than the CPMs? Since negative emotions can decrease commitment and trust toward the organization, as well as increase turnover intentions and work slowdowns (see Shepherd and Cardon, 2009), such a line of inquiry would lend itself for further research.

Future research would also benefit from a more diverse sample, so as to be able to elicit more variations among participants and contrast the parameters within which anger can yield desirable outcomes. Several instructive questions emerge in this respect. Specifically, what are the parameters (e.g. context, power relationships, gender, culture) within which negative emotions yield desirable outcomes for an organization, despite the fact that impaired cognitive processing and the accumulation of physiological strain may occur at the individual level? At the individual level, how do individuals attempt to reconcile the prescriptions of their jobs with their well-being and integrity? And lastly, what are the long-term implications (e.g. health and promotion) for individuals displaying anger as a role-obligatory behaviour and for those at the receiving end (e.g. subordinates, colleagues, etc.)?

Despite these limitations, findings of this study permit an informative glance at the role-obligatory effects of anger in the context of construction. We hope that findings of our study and the questions we raised will serve as a useful catalyst for future research.

\section{Conclusion}

In allusion to Brief and Weiss's (2002) observation that we do not know as much as we should know about the specific features of work environments that help to produce particular emotions, this study provides scholars and practitioners in the realm of leadership studies with valuable evidence to better grasp the positive and legitimate influence of anger in attaining desirables outcomes. True, scholars have amassed considerable evidence that feeling and expressing positive affect is crucial to success in both organizations and life (see Barsade and Gibson, 2007, for a review). Yet, findings of this study, especially in conjunction with other empirical studies, strongly suggest that such view fills only some pixels in the overall picture of leader effectiveness - it does not fill the entire picture.

\section{Acknowledgements}

The authors gratefully acknowledge the very constructive and detailed comments from the anonymous reviewers and Associate Editor Professor Gail T Fairhurst on earlier versions of this article. 


\section{Funding}

This study has been funded by studentships from Manchester Business School and the Economic Social Research Council (+3), as well as grants from the Statistical Society of Manchester and the Northern Leadership Academy (all UK) to the first author.

\section{References}

Agapiou A, Flanagan R, Norman G and Notman D (1998) The changing role of builders merchants in the construction supply chain. Construction Management \& Economics 16(1): 351-361.

Antonakis J (2003) Why 'emotional intelligence' does not predict leadership effectiveness: A comment on Prati, Douglas, Ferris, Ammeter, and Buckley. International Journal of Organizational Analysis 11(4): 355-361.

Antonakis J, Schriesheim CA, Donovan JA, Gopalakrishna-Pillai K, Pellegrini EK and Rossomme JL (2004) Methods for studying leadership. In: Antonakis J, Cianciolo AT and Sternberg RJ (eds) The Nature of Leadership. Thousand Oaks, CA: SAGE, 48-70.

Arnold J, Robertson IT and Cooper CL (1991) Work Psychology: Understanding Human Behaviour in the Workplace. London: Pitman.

Ashkanasy NM, Härtel CEJ and Daus CS (2002) Diversity and emotion: The new frontiers in organisational behaviour research. Journal of Management 28(3): 307-338.

Avolio BJ and Gardner WL (2005) Authentic leadership development: Getting to the root of positive forms of leadership. Leadership Quarterly 16(3): 315-338.

Baggini J (2009) Calm? Why should I be calm? The Guardian, Tuesday 3 March.

Barsade SG and Gibson DE (2007) Why does affect matter in organizations? Academy of Management Perspectives 21(1): 36-59.

Baruch Y and Jenkins S (2007) Swearing at work and permissive leadership culture: When antisocial becomes social and incivility is acceptable. Leadership \& Organisation Development Journal 28(6): 492-507.

Bass BM and Stogdill RM (1990) Bass \& Stogdill's Handbook of Leadership: Theory, Research, and Managerial Applications. New York: Free Press.

Bono JE and Ilies R (2006) Charisma, positive emotions and mood contagion. Leadership Quarterly 17(4): 317-334.

Bresnen MJ (1995) All things to all people? Perceptions, attributions, and constructions of leadership. The Leadership Quarterly 6(4): 495-513.

Brief AP and Weiss HM (2002) Organisational behaviour: Affect in the workplace. Annual Review of Psychology 53: 279-307.

Bryman A, Bresnen M, Ford J, Beardworth A and Keil T (1987) Leader orientation and organisational transience. Journal of Occupational Psychology 60(1): 15-19.

Bryman A (2004) Social Research Methods. Oxford: Oxford University Press.

Bryman A (2007) Barriers to integrating quantitative and qualitative research. Journal of Mixed Methods Research 1(1): 8-22.

Butler CJ and Chinowsky PS (2006) Emotional intelligence and leadership behaviour in construction executives. Journal of Management in Engineering 22(3): 119-125.

Calvert RE, Bailey G and Coles D (1994) Introduction to Building Management. London: Butterworth Heinemann.

Cartwright S and Gale AG (1995) Project management: Different gender, different culture? Leadership \& Organisation Development Journal 16(4): 12-16. 
Cassell C (2005) Creating the interviewer: Identity work in the management research process. Qualitative Research 5(2): 167-179.

Creswell J (1994) Research Design: Qualitative and Quantitative Approaches. London: SAGE.

Dainty ARJ, Bryman A and Price ADF (2002) Empowerment within the UK construction sector. Leadership \& Organization Development Journal 23(6): 333-342.

Dasborough M, Frick G, Lamb P and Suseno Y (2003) Emotions in mergers: A phenomenological approach. Proceedings of the annual meeting of the Academy of Management, Seattle, WA.

Dey I (1993) Qualitative Data Analysis: A User-friendly Guide for Social Scientists. London: Routledge.

Domagalski TA (1999) Emotion in organizations: Main currents. Human Relations 52(6): 833-852.

Dulaimi MF and Langford D (1999) Job behaviour of construction project managers: Determinants and assessment. Journal of Construction Engineering and Management 125(4): 256-264.

Egan J (1998) Rethinking Construction. London: HMSO.

Fairhurst G (2009) Considering context in discursive leadership research. Human Relations 62(11): 1607-1633.

Fielden SL, Davidson MJ, Gale AG and Davey CL (2000) Women in construction: The untapped resource. Construction Management \& Economics 18(1): 113-121.

Fineman S (2004) Getting the measure of emotion: And the cautionary tale of emotional intelligence. Human Relations 57(6): 719-740.

Fitness J (2008) Fear and loathing in the workplace. In: Ashkanasy NM and Cooper CL (eds) Research Companion to Emotion in Organizations. Cheltenham, UK: Edward Elgar, 61-72.

Frijda N (2007) The Laws of Emotion. Mahwah, NJ: Erlbaum.

Forgas JP (1985) Interpersonal Behaviour: The Psychology of Social Interaction. Sydney and Oxford: Pergamon Press.

Game AM (2008) Negative emotions in supervisory relationships: The role of relational models. Human Relations 61(3): 355-393.

Gardner WL, Fischer D and Hunt JG (2009) Emotional labor and leadership: A threat to authenticity? The Leadership Quarterly 20(3): 466-482.

George JM (1996) Group affective tone. In: West M (ed.) Handbook of Work Group Psychology. Chichester: Wiley, 77-93.

George JM (2000) Emotions and leadership: The role of emotional intelligence. Human Relations 53(8): 1027-1055.

Gibson DE and Roberts Callister R (2010) Anger in organizations: Review and integration. Journal of Management 36(1): 66-93.

Gibson DE and Schroeder SJ (2002) Grinning, frowning, and emotionless: Agent perceptions of power and their effect on felt and displayed emotions in influence attempts. In: Ashkanasy NM, Zerbe WJ and Härtel CEJ (eds) Managing Emotions in the Workplace. Armonk, NY: M. E. Sharpe, 184-211.

Giritli H and Oraz GT (2003) Leadership styles: Some evidence from the Turkish construction industry. Construction Management \& Economics 22(3): 253-262.

Goleman D (1998) Working with Emotional Intelligence. London: Bloomsbury.

Grint K (2000) The Arts of Leadership. Oxford: Oxford University Press.

Harris F and McCaffer R (2001) Modern Construction Management. Oxford: Blackwell.

Helay M and Perry C (2000) Comprehensive criteria to judge validity and reliability of qualitative research within the realism paradigm. Qualitative Market Research 3(3): 118-126. 
Hill A (2009) How to be happy in life: Let out your anger. The Guardian, Sunday 1 March.

Holt GD, Love PED and Nesan LJ (2000) Employee empowerment in construction: An implementation model for process improvement. Team Performance Management: An International Journal 6(3-4): 47-51.

House RJ and Aditya RN (1997) The social scientific study of leadership: Quo vadis? Journal of Management 23(3): 409-474.

Huemann M, Turner R and Keegan A (2004) Managing human resources in the project-oriented company. In: Morris PWG and Pinto JK (eds) The Wiley Guide to Managing Projects. Hoboken, NJ: Wiley, 1061-1086.

Kafetsios K, Maridaki-Kasotaki K, Zammuner VL, Zampetakis LA and Vouzas F (2009) Emotional intelligence abilities and traits in different career paths. Journal of Career Assessment 17: 367-383.

Keltner D, Gruenfeld DH and Anderson C (2003) Power, approach, and inhibition. Psychological Review 110(2): 265-284.

King N (2004) Using templates in the thematic analysis of text. In: Cassell C and Symon SG (eds) Essential Guide to Qualitative Methods in Organizational Research. London: SAGE, 256-270.

Law KS, Wong C and Song LJ (2004) The construct and criterion validity of emotional intelligence and its potential utility for management studies. Journal of Applied Psychology 89(3): 483-496.

Lawrence SA and Jordan PJ (2008) What are toxic emotions? Proceedings of the British Academy of Management Conference in Harrogate, 9-11 September.

Lewis KM (2000) When leaders display emotion: How followers respond to negative emotional expression of male and female leaders. Journal of Organizational Behaviour 21(SI): 221-234.

Liden RC and Antonakis J (2009) Considering context in psychological leadership research. Human Relations 62(11): 1-19.

Lincoln YS and Guba EG (1985) Naturalistic Inquiry. Newbury Park, CA: SAGE.

Lindebaum D and Cartwright S (in press) A critical examination of the relationship between emotional intelligence and transformational leadership. Journal of Management Studies.

Loosemore M and Chau DW (2002) Racial discrimination towards Asian operatives in the Australian construction industry. Construction Management \& Economics 20(1): 91-102.

Loosemore M and Galea N (2008) Genderlect and conflict in the Australian construction industry. Construction Management and Economics 26(2): 125-135.

Loosemore M, Dainty A and Lingard H (2003) Human Resource Management in Construction Projects: Strategic and Operational Approaches. London: Taylor \& Francis.

Lord RG, Brown DJ, Harvey JL and Hall RJ (2001) Contextual constraints on prototype generation and their multilevel consequences for leadership perceptions. Leadership Quarterly 12(3): 311-338.

Mayer JD and Salovey P (1997) What is emotional intelligence? In: Salovey P and Sluyter D (eds) Emotional Development and Emotional Intelligence: Implications for Educators. New York: Basic Books, 3-31.

Meindl JR (1995) The romance of leadership as a follower-centric theory: A social constructionist approach. Leadership Quarterly 6(3): 329-341.

Miner AG, Glomb TM and Hulin C (2005) Experience sampling mood and its correlates at work. Journal of Occupational \& Organisational Psychology 78(2): 171-193.

Mischel W (1977) The interaction of person and situation. In: Magnusson D and Endler D (eds) Personality at the Crossroads: Current Issues in Interactional Psychology. Hillsdale, NJ: Lawrence Erlbaum Associates, 333-352. 
Naoum SG (1998) Dissertation Research and Writing for Construction Students. Boston, MA: Butterworth-Heinemann.

ODPM (2004) The Egan Review: Skills for Sustainable Communities. London: ODPM (Office of the Deputy Prime Minister).

Palmer I, Wilcox-King A and Kelleher D (2004) Listening to Jack: GE's change conversations with shareholders. Journal of Organizational Change Management 17(6): 593-614.

Parkin W (1993) The public and the private: Gender, sexuality and emotion. In: Fineman S (ed.) Emotion in Organizations. London: SAGE, 167-189.

Pfeffer J (1981) Power in Organizations. Marshfield, MA: Pitman.

Poppelton S, Briner R and Kiefer T (2008) The roles of context and everyday experience in understanding work-non-work relationships: A qualitative diary study of white- and blue-collar workers. Journal of Occupational \& Organizational Psychology 81(3): 481-502.

Prati M, Douglas C, Ferris GR, Ammeter AP and Buckley MR (2003) Emotional intelligence, leadership effectiveness, and team outcomes. The International Journal of Organizational Analysis 11(4): 21-40.

Raiden AB, Dainty A and Neale RH (2004) Current barriers and possible solutions to effective project team formation and deployment within a large construction organization. International Journal of Project Management 22(4): 309-316.

Randall R, Cox T and Griffiths A (2007) Participants' accounts of a stress management intervention. Human Relations 60(8): 1181-1209.

Roberts Callister R, Gray B, Schweitzer ME, Gibson DE and Tan JS (2003) Organizational anger contexts and their relationship to outcomes of anger expressions in the workplace. 16th Annual IACM Conference, Melbourne, Australia.

Sandberg J (2000) Understanding human competence at work: An interpretative approach. Academy of Management Journal 43(1): 9-25.

Sandberg J (2005) How do we justify knowledge produced within interpretive approaches? Organizational Research Methods 8(1): 41-68.

Schneider B (1987) The people make the place. Personnel Psychology 40(3): 437-453.

Shepherd DA and Cardon MS (2009) Negative emotional reactions to project failure and the self-compassion to learn from the experience. Journal of Management Studies 46(6): 923-949.

Smithers GL and Walker DHT (2000) The effect of the workplace on motivation and demotivation of construction professionals. Construction Management \& Economics 18(7): 833-841.

Smyth H (2000) Marketing and Selling Construction Services. Oxford: Blackwell.

Solomon R (1993) The Passions: Emotions and the Meaning of Life. Indianapolis, IN: Hackett Publishing.

Stanley RO and Burrows GD (2001) Varieties and functions of human emotion. In: Payne R and Cooper CL (eds) Emotions at Work: Theory, Research, and Application for Management. Chichester: Wiley, 3-19.

Staw BM and Ross J (1989) Understanding behaviour in escalation situations. Science 246(4927): 216-220.

Steptoe A, Cropley M, Griffith J and Kirschbaum C (2000) Job strain and anger expression predict early morning elevations in salivary cortisol. Psychosomatic Medicine 62(2): 286-292.

Strauss A and Corbin J (1998) Basics of Qualitative Research: Techniques and Procedures for Developing Grounded Theory. London: SAGE. 
Tiedens LZ (2001) Anger and advancement versus sadness and subjugation: The effect of negative emotion expressions on social status conferral. Journal of Personality and Social Psychology 80(1): 86-94.

Toor SR and Ofori G (2008) Leadership for future construction industry: Agenda for authentic leadership. International Journal of Project Management 26(6): 620-630.

van Kleef GA, De Dreu CKW and Manstead ASR (2004) The interpersonal effects of anger and happiness in negotiations: A motivated information processing approach. Journal of Personality and Social Psychology 87(4): 510-528.

Zaccaro SJ and Klimoski RJ (2001) The Nature of Organizational Leadership: Understanding the Performance Imperatives Confronting Today's Leaders. San Francisco, CA: Jossey-Bass.

Zeelenberg M, Nelissen R, Breugelmans SH and Pieters R (2008) On emotion specificity in decision making: Why feeling is for doing. Judgment and Decision Making 3(1): 18-27.

Dirk Lindebaum is a Lecturer in Management at the University of Liverpool Management School. Among his current research interests is the construct of Emotional Intelligence, which he examines in light of the tensions individuals experience when they attempt to reconcile organizational interests and their well-being, and the potential for resistance that may result from this tension. His work has been published in Academy of Management Learning and Education and Journal of Management Studies. [Email: d.lindebaum@liverpool.ac.uk].

Sandra Fielden is a Senior Lecturer in Organizational Psychology at Manchester Business School and Co-Director of the Centre for Equality and Diversity at Work. Sandra is a chartered occupational psychologist and a council member of the British Academy of Management. She is also the Editor of Gender in Management: An International Journal for which she was awarded Editor of the Year 2002 and 2004 and is co-editor of the recently published books (with MJ Davidson) Individual Diversity and Psychology in Organisations and International Handbook of Women and Small Business Entrepreneurship. [Email: sandra.fielden@mbs.ac.uk] 